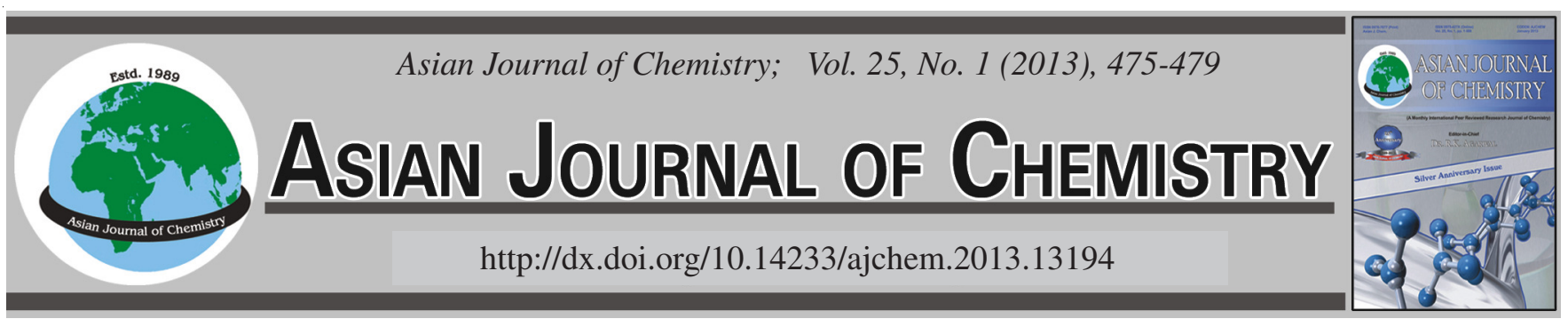

\title{
Determination of the Distribution of Acrylic Comonomers in Free Radicals Polymers
}

\author{
Adelaida Andoni ${ }^{1, *}$, Jasper J. Michels ${ }^{2}$, Efrosini Kokalari (Teli) ${ }^{1}$, Krenaida Taraj ${ }^{1}$ and Armand Çomo ${ }^{1}$
}

${ }^{1}$ Department of Chemistry, Faculty of Natural Sciences, Blv. "Zog I", 1001, University of Tirana, Tirana, Albania

${ }^{2}$ TNO Science and Industry, P.O. Box 6235, 5600 HE Eindhoven, The Netherlands

*Corresponding author: E-mail: adelaida.andoni@unitir.edu.al; adelaida.andoni@fshn.edu.al

(Received: 7 December 2011;

Accepted: 30 July 2012)

AJC-11903

\begin{abstract}
Some acrylate monomers have been synthesized and copolymerized by means of free radical polymerization with methyl methacrylate and butyl methacrylate. These monomers are known to introduce the desired functionality and tune the properties of the resulting polymer. The synthesized monomers and the polymers have been characterized with NMR spectroscopy. The latter is utilized to study the polymer composition and verify the distribution of the monomers in the copolymer chain. The reactivity ratios have been estimated and concluded moderately random distribution of the monomers in the copolymer chain.
\end{abstract}

Key Words: Acrylate monomers, Free radical polymerization, Reacitivity ratios.

\section{INTRODUCTION}

One of the most common and useful reactions to make polymers is free radical polymerization. This polymerization is used to make polymers from monomers containing carboncarbon double bonds such as acrylates, vinyl monomers, allylic monomers etc. Some acrylate monomers have been used by Voss et al. ${ }^{1}$ and Wouters et al. ${ }^{2}$ to study the effect of pendant functionality on the thermal and physical properties of polymers obtained by the reversible addition-fragmentation chain-transfer (RAFT) polymerization. The methacrylate copolymers studied by these authors contained $n$-butyl-methacrylate and methyl methacrylate (MMA) to control the glass transition temperature of the final polymer and a minor fraction of one of the monomers displayed in Fig. 1. These monomers were chosen for their particular interacting capabilities (H-bonding or $\pi-\pi$ interaction). In this study, the authors assumed that the distribution of comonomers in the RAFT polymers is random and nevertheless no further investigation was done to prove this supposition.

We extended the work of Voss et al. ${ }^{1}$ and Wouters et al. ${ }^{2}$ by performing free radical copolymerization of monomers $\mathbf{3}$ and $\mathbf{5}$ with methyl methacrylate and butyl-methacrylate with the aim to estimate the reactivity ratios, giving though insight in the monomer distribution in the polymer chain. The copolymerizations of monomers $\mathbf{3}$ and $\mathbf{5}$ with both methyl methacrylate and butyl methacrylate were carried out. Subsequently, the reactivy ratios are determined and the compositions of the present polymers are presented. ${ }^{1} \mathrm{H}$ NMR spectroscopy is employed to study the polymer composition.

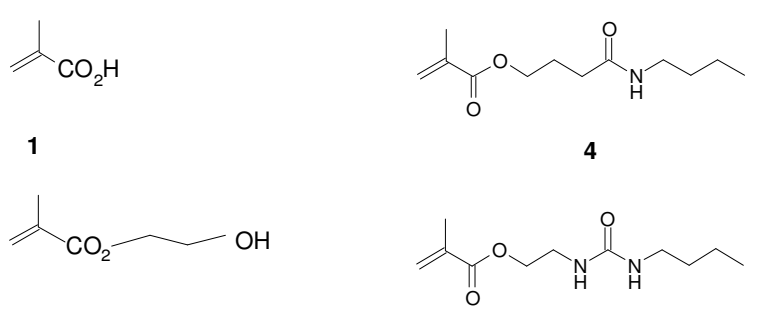

2

5

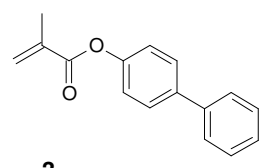

Fig. 1. Chemical structures of the monomers 1, 2, 3, 4 and 5

Free radical polymerization: Three main kinetic steps occur during free radical polymerization: (1) initiation, (2) propagation and (3) termination. Free radicals are usually generated by the addition of an initiator. The latter forms radicals when heated or irradiated. Two common examples of compounds, which afford free radicals are benzoyl peroxide (BPO) (Fig. 2a) and 2-2'-azo-bis-isobutyrylnitrile (AIBN) (Fig. 2b).
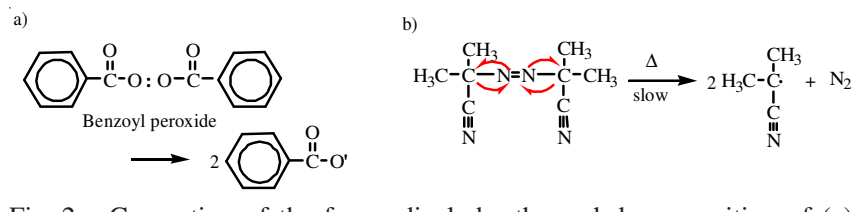

Fig. 2. Generation of the free radicals by thermal decomposition of (a) benzoyl peroxide; (b) AIBN to form free radicals 
The process starts with the initiation, which involves two reactions. The first one is the production of the free radicals. The initiator will split to give a pair of radicals $\mathrm{R}$ : $\mathrm{I}_{2} \stackrel{\mathrm{k}_{\mathrm{d}}}{\longrightarrow} 2 \mathrm{R}^{\bullet}$. The carbon-carbon double bond, for instance, of an acrylate has a pair of electrons, which is attacked by the free radicals. The unpaired electrons of the radical combine with one of the electrons of the carbon-carbon double bond by creating a new pair of electrons and therefore making a new chemical bond between the free radical and the double bond of the monomer:

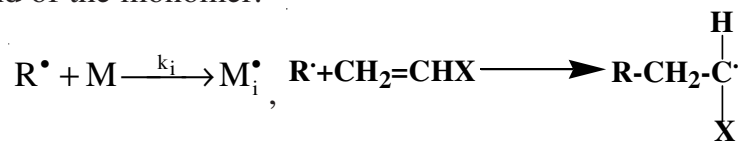

The unpaired electron created after the double bond has been attacked associates itself with the carbon atom which is not bonded to the initiator fragment. Therefore the chain ends with a free radical can be combined with another carboncarbon double bond of the next monomer and the process results in propagation. Thus a polymer is formed. As propagation continues and each monomer unit is added, the radical has the same identity as the radical before except it is larger by unit: $\mathbf{M}_{1}^{\bullet}+\mathrm{M} \stackrel{\mathrm{kP}_{\mathrm{P}}}{\longrightarrow} \mathbf{M}_{2}^{\bullet}$. Propagation with growth of the chain to higher molecular weight polymer takes place rapidly but at some point the propagating radical at the end of the polymer chain stops growing and terminates.

Reactivity ratios: In a free radical copolymerization of two monomers $\mathrm{M}_{1}$ and $\mathrm{M}_{2}$ four competing propagation steps are considered ${ }^{3}$ (Fig. 3):

$$
\begin{aligned}
& \cdots \cdots M_{1}^{\bullet}+M_{1} \stackrel{\mathrm{k}_{11}}{\longrightarrow} \cdots \cdots \cdot \mathrm{M}_{1}^{\bullet} \\
& \cdots \cdots \mathrm{M}_{1}^{\bullet}+\mathrm{M}_{2} \stackrel{\mathrm{k}_{12}}{\longrightarrow} \cdots \cdots \mathrm{M}_{2}^{\bullet} \\
& \cdots \cdots \mathrm{M}_{2}^{\bullet}+\mathrm{M}_{1} \stackrel{\mathrm{k}_{21}}{\longrightarrow} \cdots \cdots \mathrm{M}_{1}^{\bullet} \\
& \cdots \cdots \mathrm{M}_{2}^{\bullet}+\mathrm{M}_{2} \stackrel{\mathrm{k}_{22}}{\longrightarrow} \cdots \cdots \mathrm{M}_{2}^{\bullet}
\end{aligned}
$$

Fig. 3. Reaction scheme of the copolymerization of $\mathrm{M}_{1}$ and $\mathrm{M}_{2}$

The propagating chain that ends with $\mathbf{M}_{1}$ can either react with a monomer of type $\mathrm{M}_{1}$ or of type $\mathrm{M}_{2}$. The propagating chain that ends with $\mathrm{M}_{2}$ can react with a monomer unit of type $M_{1}$ or of type $M_{2}$. The rate constant for the reaction of the propagating chain that ends with $\hat{M}_{1}$ and reacts with another $\mathrm{M}_{1}$ to the end of the chain is $\mathrm{k}_{11}$ and the rate constant for the reaction of the propagating chain that ends with $\mathbf{M}_{2}$ and reacts with $\mathrm{M}_{1}$ to the end of the chain is $\mathrm{k}_{21}$ and so on. Monomers 1 and 2 are consumed as indicated by the reaction scheme in Fig. 3. The change in monomer concentrations $M_{1}$ and $M_{2}$ is expressed by equation (1) and $(2)^{3}$ :

$$
\begin{aligned}
& -\frac{\mathrm{d}\left[\mathrm{M}_{1}\right]}{\mathrm{dt}}=\mathrm{k}_{11}\left[\cdots \cdots \mathrm{M}_{1}^{\cdot}\right]\left[\mathrm{M}_{1}\right]+\mathrm{k}_{21}\left[\cdots \cdots \mathrm{M}_{2}^{\bullet}\right]\left[\mathrm{M}_{1}\right] \\
& -\frac{\mathrm{d}\left[\mathrm{M}_{2}\right]}{\mathrm{dt}}=\mathrm{k}_{12}\left[\cdots \cdots \mathrm{M}_{1}^{\cdot}\right]\left[\mathrm{M}_{2}\right]+\mathrm{k}_{22}\left[\cdots \cdots \mathrm{M}_{2}^{\cdot}\right]\left[\mathrm{M}_{2}\right]
\end{aligned}
$$

Equation (1) is divided by eqn. (2) to give the copolymer composition equation (3):

$$
\frac{\mathrm{d}\left[\mathrm{M}_{1}\right]}{\mathrm{d}\left[\mathrm{M}_{2}\right]}=\frac{\mathrm{k}_{11}\left[\cdots \cdots \mathrm{M}_{1}^{\cdot}\right]\left[\mathrm{M}_{1}\right]+\mathrm{k}_{21}\left[\cdots \cdots \mathrm{M}_{2}^{\cdot}\right]\left[\mathrm{M}_{1}\right]}{\mathrm{k}_{12}\left[\cdots \cdots \mathrm{M}_{1}^{\cdot}\right]\left[\mathrm{M}_{2}\right]+\mathrm{k}_{22}\left[\cdots \cdots \mathrm{M}_{2}^{\cdot}\right]\left[\mathrm{M}_{2}\right]}
$$

The low concentrations of the radical chain-ends in the systems are difficult to be determined experimentally. For this reason a steady state approximation is applied for species ....... $\mathrm{M}_{1}$ and ....... $\mathrm{M}_{2}$ to remove the corresponding factors from the eqn. (3). The interconversion between the two species must be equal in order for the concentrations of each to remain constant and hence the rates of reactions with rate constant $\mathrm{k}_{12}$ and $\mathrm{k}_{21}$ must be equal: $\mathrm{k}_{21}\left[\cdots \cdots \cdot \mathrm{M}_{2}^{*}\right]\left[\mathrm{M}_{1}\right]=\mathrm{k}_{12}\left[\cdots \cdots \mathrm{M}_{1}^{*}\right]\left[\mathrm{M}_{2}\right](4)^{4}$. Rearrangement of eqn. (4) and combination with eqn. (3) gives eqn. (5):

$$
\frac{\mathrm{d}\left[\mathrm{M}_{1}\right]}{\mathrm{d}\left[\mathrm{M}_{2}\right]}=\frac{\frac{\mathrm{k}_{11} \mathrm{k}_{21}\left[\cdots \cdots \mathrm{M}_{2}^{\bullet}\right]\left[\mathrm{M}_{1}\right]^{2}}{\mathrm{k}_{12}\left[\mathrm{M}_{2}\right]}+\mathrm{k}_{21}\left[\cdots \cdots \mathrm{M}_{2}^{\bullet}\right]\left[\mathrm{M}_{1}\right]}{\mathrm{k}_{22}\left[\cdots \cdots \mathrm{M}_{2}^{\cdot}\right]\left[\mathrm{M}_{2}\right]+\mathrm{k}_{21}\left[\cdots \cdots \mathrm{M}_{2}^{\cdot}\right]\left[\mathrm{M}_{1}\right]}
$$

This equation can be further simplified by dividing the right side (nominator and denominator by $\mathrm{k}_{21}\left[\cdots \cdots \mathrm{M}_{2}^{\bullet}\right]\left[\mathrm{M}_{1}\right]^{4}$. The results are then combined with the parameters $r_{1}$ and $r_{2}$, which are defined to be the reactivity ratios: $r_{1}=k_{11} / k_{12}$ and $r_{2}$ $=\mathrm{k}_{22} / \mathrm{k}_{21}(6)$. The most familiar form of the copolymerization composition equation is then obtained:

$$
\frac{\mathrm{d}\left[\mathrm{M}_{1}\right]}{\mathrm{d}\left[\mathrm{M}_{2}\right]}=\frac{\left[\mathrm{M}_{1}\right]\left(\mathrm{r}_{1}\left[\mathrm{M}_{1}\right]+\left[\mathrm{M}_{2}\right]\right)}{\left[\mathrm{M}_{2}\right]\left(\left[\mathrm{M}_{1}\right]+\mathrm{r}_{2}\left[\mathrm{M}_{2}\right]\right)}
$$

At low conversion, where the concentration of monomers does not change appreciably equation (7) can be approximated by equation (8): $m_{1} / m_{2}=M_{1}\left(r_{1} M_{1}+M_{2}\right) / M_{2}\left(M_{1}+r_{2} M_{2}\right)$, where, $M_{1}$ is the mole fraction of monomer 1 in the reaction system (amount in the feed) and $\mathrm{M}_{2}$ is the mole fraction of monomer 2 in the reaction system (amount in the feed). $\mathrm{m}_{1}$ and $\mathrm{m}_{2}$ are the mole fractions of monomer 1 and 3 in the polymer composed entirely of the two monomers (estimated from the NMR spectra after short polymerizations). The copolymer composition equation defines the molar ratios of the two monomers that are incorporated into the copolymer. A reactivity ratio expresses the ratio of the reactivity of a growing chain end towards its own monomer and that towards the other monomer ${ }^{3}$. Lastly, if $r_{1}=1$ and $r_{2}=1$ the monomers are randomly distributed:- $-\mathrm{M}_{1} \mathrm{M}_{1} \mathrm{M}_{2} \mathrm{M}_{2} \mathrm{M}_{2} \mathrm{M}_{1} \mathrm{M}_{2} \mathrm{M}_{1} \mathrm{M}_{1}--$. If $r_{1}<<1$ and $r_{2}<<1$ the copolymer contains one or more long uninterrupted sequences of each of the comonomer species giving a block copolymer: - $-\mathrm{M}_{1} \mathrm{M}_{1} \mathrm{M}_{1} \mathrm{M}_{1}-\mathrm{M}_{2} \mathrm{M}_{2} \mathrm{M}_{2} \mathrm{M}_{2}--$. If $r_{1}<<1$ and $r_{2}<<1$ the polymer has equimolar compositions with a regularly perfect alternating distribution of monomer units. These are alternating copolymers: - - $\mathrm{M}_{1} \mathrm{M}_{2} \mathrm{M}_{1} \mathrm{M}_{2} \mathrm{M}_{1}$ $\mathrm{M}_{2} \mathrm{M}_{1} \mathrm{M}_{2--}$.

\section{EXPERIMENTAL}

Monomer synthesis: All the chemicals used for the synthesis of monomers $\mathbf{3}$ and $\mathbf{5}$ were purchased from Aldrich and used as received. Monomers $\mathbf{3}$ and $\mathbf{5}$ were synthesized as described below. NMR spectra were recorded on a Varian Mercury 400 spectrometer.

Synthesis of monomer 3 (Fig. 4)

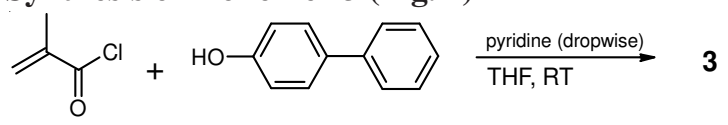

Fig. 4. Reaction scheme for the synthesis of the monomer $\mathbf{3}$ 
Reaction: 4-Phenyl phenol $\left(\mathrm{C}_{12} \mathrm{H}_{10} \mathrm{O}, \mathrm{M}_{\mathrm{w}}=170.22 \mathrm{~g} / \mathrm{mol}\right.$, $20 \mathrm{~g}, 117 \mathrm{mmol}$ ) was dissolved in $100 \mathrm{~mL}$ tertrahydrofuran in a $250 \mathrm{~mL} 3$-neck flask, equipped with a dropping funnel (preferably positioned at the middle neck), nitrogen inlet and a stopper. Methacryloyl chloride $\left(\mathrm{C}_{4} \mathrm{H}_{5} \mathrm{ClO}, \mathrm{M}_{\mathrm{w}}=104.54\right.$ $\mathrm{g} / \mathrm{mol}, 13.94 \mathrm{~mL}, 15 \mathrm{~g}, \mathrm{~d}=1.076 \mathrm{~g} / \mathrm{mL}, 141 \mathrm{mmol}$ ) was added to the stirring solution using a syringe. The dropping funnel was charged with pyridine $\left(\mathrm{C}_{5} \mathrm{H}_{5} \mathrm{~N}, \mathrm{M}_{\mathrm{w}}=79.11 \mathrm{~g} / \mathrm{mol}, 11.34\right.$ $\mathrm{mL}, \mathrm{d}=0.97 \mathrm{~g} / \mathrm{mL}, 11 \mathrm{~g}, 141 \mathrm{mmol})$. The whole set-up was kept under nitrogen atmosphere. Pyridine was added dropwise to the stirring solution while maintaining the reaction mixture at ${ }^{\circ} \mathrm{C}$. Upon addition of the pyridine a white precipitate formed. The mixture was stirred over night at room temperature under nitrogen atmosphere. The reaction was monitored by TLC using chloroform as eluent. The reaction was over after $24 \mathrm{~h}$.

Work up: $100 \mathrm{~mL}$ water and $200 \mathrm{~mL}$ ethyl acetate were added to the reaction mixture. The layers were mixed by shaking properly in a separating funnel. The organic layer was separated and washed with $100 \mathrm{~mL}$ water and $\mathrm{HCl}(0.001 \mathrm{M})$ to remove pyridine residues. The combined aqueous layers were extracted with ethyl acetate. The organic layers were dried on magnesium sulphate followed by filtration and evaporation of the solvent under reduced pressure. The purity of the crude product was checked by TLC (chloroform used as solvent) and ${ }^{1} \mathrm{H}$ NMR.

Purification: The obtained crude product was dissolved in methanol in a three neck flask equipped with a reflux condenser stirred and heated (with heating gun) till the solution becomes clear. The solution cooled down and crystallization occurred. The solution was afterwards filtrated. The fine white crystals were dried under reduced pressure to remove traces of methanol. Yield of product was $70 \%$.

Characterization: ${ }^{1} \mathrm{H} \mathrm{NMR}\left(400 \mathrm{MHz}, \mathrm{CDCl}_{3}\right) \delta(\mathrm{ppm})$ 7.61-7.18, (m, 9H, $\left.\mathrm{C}_{6} \mathrm{H}_{5} \mathrm{C}_{6} \mathrm{H}_{4} \mathrm{OCO}\right)$, 6.37, 5.77 (s, 2H, $\mathrm{CCH}_{2}$ ), 2.08, (s, 3H, $\left.\mathrm{CH}_{3} \mathrm{C}\right) ;{ }^{13} \mathrm{C} \mathrm{NMR}\left(400 \mathrm{MHz}, \mathrm{CDCl}_{3}\right) \delta(\mathrm{ppm})$ 165.91 (ArOCO), $150.31\left(\mathrm{CCH}_{3}\right), 140.37,138.86,135.82$, $128.77,128.13,127.30,127.10,126.75\left(=\mathrm{CH}_{2}\right), 121.85,18.40$ $\left(\mathrm{CH}_{3}\right)$. Elementary analysis calculated for $\mathrm{C}_{16} \mathrm{H}_{12} \mathrm{O}_{2}, \mathrm{C}, 80.63$ $\%$; H, $14.14 \%$. Found C, $80.65 \%$; H, $5.69 \%$.

Synthesis of monomer 5 (Fig. 5)

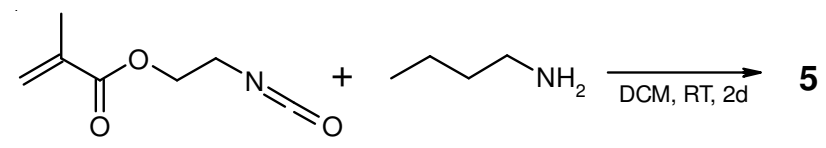

Fig. 5. Reaction scheme for the synthesis of the monomer $\mathbf{5}$

Reaction: $30 \mathrm{~mL}$ of 2-methacryloyl oxyethyl isocyanate $\left(\mathrm{C}_{7} \mathrm{H}_{9} \mathrm{NO}_{9}, \mathrm{M}_{\mathrm{w}}=145 \mathrm{~g} / \mathrm{mol}, 33.83 \mathrm{~g}, \mathrm{~d}=1.098 \mathrm{~g} / \mathrm{mL}, 233\right.$ $\mathrm{mmol}$ ) was dissolved in $250 \mathrm{~mL}$ dichloromethane in a 500 $\mathrm{mL}$ 3-neck flask equipped with a dropping funnel, nitrogen inlet and a stopper. The dropping funnel was filled with $n$-butyl amine $\left(\mathrm{C}_{4} \mathrm{H}_{11} \mathrm{~N}, \mathrm{M}_{\mathrm{w}}=73.16 \mathrm{~g} / \mathrm{mol}, 27 \mathrm{~mL}, \mathrm{~d}=0.74\right.$ $\mathrm{g} / \mathrm{mL}, 20 \mathrm{~g}, 273 \mathrm{mmol}$ ) using a syringe. The whole set-up was kept under nitrogen atmosphere. The reaction mixture was cooled to $0{ }^{\circ} \mathrm{C}$ using an ice bath. $n$-Butyl amine was added dropwise while maintaining the reaction mixture at $0^{\circ} \mathrm{C}$. Subsequently, the reaction mixture was stirred for 2 days at room temperature. The reaction was monitored with chloroform was used as eluent comparing the reaction mixture with the starting material 2-methacryloyl oxyethyl isocyanate as a reference. Reaction was completed after $48 \mathrm{~h}$.

Work up: The organic layer was washed with $0.1 \mathrm{M} \mathrm{HCl}$ in a separating funnel till the $\mathrm{pH}$ of the aqueous layer remained acidic. The aqueous layer was extracted with $200 \mathrm{~mL}$ dichloromethane and the combined organic layers were dried on $\mathrm{MgSO}_{4}$ followed by filtration and evaporation under reduced pressure to remove the solvent. The obtained product was a white powder (yield $=80 \%$ ).

Purification: ${ }^{1} \mathrm{H}$ NMR and TLC indicated $99 \%$ purity, therefore no purification was carried out.

Characterization: ${ }^{1} \mathrm{H} \mathrm{NMR},\left(400 \mathrm{MHz}, \mathrm{CDCl}_{3}\right) \delta(\mathrm{ppm})$, 6.12, 5.59 (s, 2H, $\mathrm{CCH}_{2}$ ), 4.59 (s, 1H, NHCONH), 4.36 (s, $1 \mathrm{H}, \mathrm{NHCONH}), 4.24\left(\mathrm{t}, 2 \mathrm{H}, 3 \mathrm{~J}=5.4 \mathrm{~Hz}, \mathrm{COOCH}_{2} \mathrm{CH}_{2}\right.$ ), $3.51\left(\mathrm{t}, 2 \mathrm{H},{ }^{3} \mathrm{~J}=5.2 \mathrm{~Hz}, \mathrm{OCH}_{2} \mathrm{CH}_{2} \mathrm{NH}\right), 3.16\left(\mathrm{t}, 2 \mathrm{H},{ }^{3} \mathrm{~J}=7.2\right.$ $\mathrm{Hz}, \mathrm{CONHCH}_{2} \mathrm{CH}_{2}$ ), 1.95 (s, 3H, $\left.\mathrm{CH}_{3} \mathrm{CCH}_{2}\right), 1.48$ (p, $2 \mathrm{H},{ }^{3}$ $J=7.1 \mathrm{~Hz}, \mathrm{NHCH}_{2} \mathrm{CH}_{2} \mathrm{CH}_{2}$ ), 1.35 (seq, $2 \mathrm{H},{ }^{3} J=7.4 \mathrm{~Hz}$, $\mathrm{CH}_{2} \mathrm{CH}_{2} \mathrm{CH}_{3}$ ), 0.92 (t, $\left.3 \mathrm{H},{ }^{3} \mathrm{~J}=7.2 \mathrm{~Hz}, \mathrm{CH}_{2} \mathrm{CH}_{2} \mathrm{CH}_{3}\right) ;{ }^{13} \mathrm{C} \mathrm{NMR}$ $\left(400 \mathrm{MHz}, \mathrm{CDCl}_{3}\right) \delta(\mathrm{ppm}), 167.20(\mathrm{HNCONH}), 159.08$ (COO), $135.86\left(\mathrm{CCH}_{3}\right), 125.64\left(=\mathrm{CH}_{2}\right), 64.04,39.75,38.86$, $32.20,19.86,18.03,13.59$. Elementary analysis calculated for $\mathrm{C}_{11} \mathrm{H}_{20} \mathrm{O}_{3} \mathrm{~N}_{2}$ : C, $57.86 \% ; \mathrm{H}, 8.85 \% ; \mathrm{N}, 12.27 \%$. Found: $\mathrm{C}$, $57.58 \%$; H, $8.63 \%$; N, $11.99 \%$.

Polymer syntheses: All the chemicals used for the synthesis of polymers were purchased from Aldrich and used as received. NMR spectra were recorded on a Varian Mercury 400 spectrometer. A typical polymerization involves $50 \mathrm{mmol}$ of monomer and $25 \mathrm{mmol}$ of 2-2'-azo-bis-isobutyrylnitrile (AIBN). 8 Sets of experiments were carried out for 8 copolymerizations. Samples were taken from the reactions mixture at low conversion (typically below $10 \%$ ). The conversions were estimated by dividing the polymer weight with the theoretical weight of the monomers present in $1 \mathrm{~mL}$ of reaction mixture multiplied by 100 (assuming the density of the monomers to be $1 \mathrm{~g} / \mathrm{mL}$ ).

\section{Polymerizations of monomer 5 with methyl methacrylate}

Experiment 1: $3.35 \mathrm{~g}$ methyl methacrylate $(33.5 \mathrm{mmol})$, $3.76 \mathrm{~g}$ monomer $5(16.5 \mathrm{mmol})$ and $41 \mathrm{mg}$ AIBN initiator were dissolved in $7 \mathrm{~mL}$ dioxane in a $100 \mathrm{~mL}$ flask equipped with a stirrer bar. The reaction mixture was purged with nitrogen for $20 \mathrm{~min}$ and heated afterwards at $60{ }^{\circ} \mathrm{C} .1 \mathrm{~mL}$ sample was taken from the reaction mixture after $40 \mathrm{~min}$ of polymerization and precipitated in the solution of methanol/ water $=70 \% / 30 \%$. The polymer was dried under reduced pressure and weighed afterwards $(0.013 \mathrm{~g})$. Conversion $=$ ca. 3 wt $\%$.

Experiment 2: $1.65 \mathrm{~g}$ methyl methacrylate $(16.5 \mathrm{mmol})$, $7.65 \mathrm{~g}$ monomer $5(33.5 \mathrm{mmol})$ and $41 \mathrm{mg}$ AIBN were dissolved in $14 \mathrm{~mL}$ dioxane (the larger amount of the monomer 5 used in this case required twice amount of the solvent for proper dissolution of the monomer in dioxane), followed by purging for $20 \mathrm{~min}$ with nitrogen and heating afterwards at 60 ${ }^{\circ} \mathrm{C}$. $1 \mathrm{~mL}$ sample was taken after $40 \mathrm{~min}$ of polymerization followed by the precipitation of the polymer in the solution of methanol/water $=70 \% / 30 \%$. Polymer was dried under reduced pressure and weighed afterwards $(0.027 \mathrm{~g})$. Conversion $=c a .6 .75 \mathrm{wt} \%$. 


\section{Polymerizations of monomer 5 with butyl-methacrylate}

Experiment 3: $2.35 \mathrm{~g}$ butyl-methacrylate (16.5 mmol), $7.65 \mathrm{~g}$ monomer $5(33.5 \mathrm{mmol})$ and $42 \mathrm{mg}$ AIBN were dissolved in $7 \mathrm{~mL}$ dioxane. After 20 min purging with nitrogen the reaction mixture was heated at $60^{\circ} \mathrm{C} .1 .5 \mathrm{~mL}$ sample was taken after 25 min of polymerization. The polymer was precipitated in the solution of $\mathrm{MeOH} / \mathrm{H}_{2} \mathrm{O}=70 \% / 30 \%$, dried under reduced pressure and weighed afterwards $(0.068 \mathrm{~g})$. Conversion $=c a .7 .5 \mathrm{wt} \%$.

Experiment 4: $4.76 \mathrm{~g}$ butyl-methacrylate $(33.5 \mathrm{mmol})$, $3.76 \mathrm{~g}$ monomer 5 ( $16.5 \mathrm{mmol}$ ) and $42 \mathrm{mg}$ AIBN were dissolved in $7 \mathrm{~mL}$ dioxane followed by 20 min purging with nitrogen. The reaction mixture was heated at $60{ }^{\circ} \mathrm{C}$ afterwards. $1 \mathrm{~mL}$ sample was taken after 15 min and precipitated in $\mathrm{CH}_{3} \mathrm{OH} /$ $\mathrm{H}_{2} \mathrm{O}=70 \% / 30 \%$. The polymer was dried under reduced pressure and weighed afterwards $(0.025 \mathrm{~g})$. Conversion $=c a$. 4.63 wt $\%$.

\section{Polymerizations of monomer 3 with methyl methacrylate}

Experiment 5: $0.42 \mathrm{~g}$ methyl methacrylate (4.2 mmol), $1.99 \mathrm{~g}$ monomer $3(8.4 \mathrm{mmol})$ and $10.5 \mathrm{mg}$ AIBN were dissolved in $7 \mathrm{~mL}$ dioxane (the amounts were divided by 4 due to the lack of the starting material). The same procedure was followed as in the former experiments. $1 \mathrm{~mL}$ sample was taken after 45 min of polymerization and precipitated in hexane. The polymer was dried under reduced pressure and weighed afterwards $(0.013 \mathrm{~g})$. Conversion $=c a .5 .09 \mathrm{wt} \%$.

Experiment 6: $0.84 \mathrm{~g}$ methyl methacrylate $(8.4 \mathrm{mmol})$, $0.98 \mathrm{~g}$ monomer 3 (4.2 mmol) and $10.5 \mathrm{mg}$ AIBN were dissolved in $7 \mathrm{~mL}$ dioxane. The same procedure was carried out as above mentioned. $1 \mathrm{~mL}$ sample of polymer was taken after $1 \mathrm{~h}$ of polymerization and precipitated in hexane. The polymer was dried under reduced pressure and weighed afterwards $(0.021 \mathrm{~g})$. Conversion $=c a .10 \mathrm{wt} \%$.

\section{Polymerizations of monomer 3 with butyl-methacrylate}

Experiment 7: $1.19 \mathrm{~g}$ butyl-methacrylate $(8.4 \mathrm{mmol})$, $0.98 \mathrm{~g}$ monomer $3(4.2 \mathrm{mmol})$ and $10.5 \mathrm{mg}$ AIBN were dissolved in $7 \mathrm{~mL}$ dioxane. The reaction mixture was purged for 20 min with nitrogen and heated afterwards at $60^{\circ} \mathrm{C} .0 .5 \mathrm{~mL}$ sample of polymer was taken after $20 \mathrm{~min}$ of polymerization and precipitated in hexane. The polymer was dried under reduced pressure and weighed afterwards $(0.019 \mathrm{~g})$. Conversion $=c a .15 \mathrm{wt} \%$.

Experiment 8: $0.59 \mathrm{~g}$ butyl-methacrylate (4.2 mmol), $1.99 \mathrm{~g}$ ( $8.4 \mathrm{mmol})$ monomer 3 and $10.5 \mathrm{mg}$ AIBN were dissolved in $5 \mathrm{~mL}$ dioxane. The reaction mixture was purged for $20 \mathrm{~min}$ with nitrogen and heated afterwards at $60^{\circ} \mathrm{C} .1 \mathrm{~mL}$ sample of polymer was taken after $50 \mathrm{~min}$ of polymerization and precipitated in hexane. The polymer was dried under reduced pressure and weighed afterwards $(0.018 \mathrm{~g})$. Conversion $=4.78 \mathrm{wt} \%$.

NMR spectroscopy: NMR spectra for the copolymers were recorded $400 \mathrm{MHz}$ NMR spectrometer. ${ }^{1} \mathrm{H}$ NMR chemical shifts were given relative to TMS $(0.00 \mathrm{ppm}) .{ }^{13} \mathrm{C}$ Chemical shifts are given relative to $\mathrm{CDCl}_{3}(77.00 \mathrm{ppm})$.

NMR spectroscopy of polymers: Polymer 1 and 2 obtained from experiment 1 and 2 respectively were dissolved in $\mathrm{CD}_{3} \mathrm{OD}$. For the calculation of $\mathrm{m}_{1}$ and $\mathrm{m}_{2}$ the protons indicated with arrows in the structures of Fig. 6 were analyzed in the NMR spectra.<smiles>C=C(C)C(=C)OC</smiles>

Methyl methacrylate

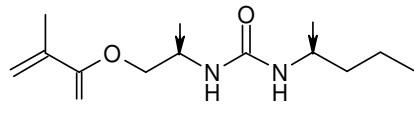

5
Fig. 6. Chemical structure of methyl methacrylate and monomer $\mathbf{5}$ where protons analyzed in the NMR spectra are indicated with arrows

Polymers obtained from the experiments 3 and 4 were dissolved in $\mathrm{CD}_{3} \mathrm{OD}$ as well. For the butyl-methacrylate and monomer 5 the protons indicated with arrows in the structures of Fig. 7 were analyzed for the calculations $\left(m_{1}\right.$ and $\left.m_{2}\right)$ in the NMR spectra.<smiles>C=C(C)C(=C)OCCCC</smiles>

Buty methacrylate

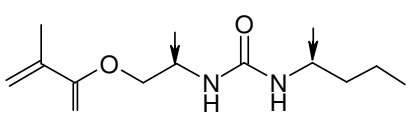

5
Fig. 7. Chemical structure of butyl-methacrylate and monomer $\mathbf{5}$ where protons analyzed in the NMR spectra are indicated with arrows

Polymers obtained from the experiments 5 and 6 were dissolved in $\mathrm{CD}_{2} \mathrm{Cl}_{2}$. For the calculation of $\mathrm{m}_{1}$ and $\mathrm{m}_{2}$ the protons in the region of the aromatic groups $(9 \mathrm{H})$ and the protons of the $\mathrm{OCH}_{3}(3 \mathrm{H})$ group of the methyl methacrylate were analyzed in the NMR spectra (Fig. 8 as well).

Polymers obtained from the experiments 7 and 8 were dissolved in $\mathrm{CD}_{2} \mathrm{Cl}_{2}$ as well. For the calculation of $\mathrm{m}_{1}$ and $\mathrm{m}_{2}$ the protons indicated with arrows in the structures of Fig. 8 were analyzed in the NMR spectra.<smiles>C=C(C)C(=C)OCCCC</smiles>

Butyl methacrylate

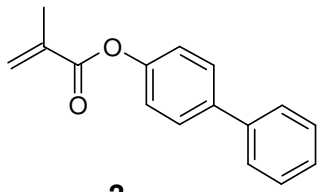

Fig. 8. Chemical structure of butyl-methacrylate and monomer $\mathbf{3}$ where protons analyzed in the NMR spectra are indicated with arrows

\section{RESULTS AND DISCUSSION}

Determination of reactivity ratios: Reactivity ratios were determined for the copolymerization of monomers $\mathbf{3}$ and $\mathbf{5}$ with methyl methacrylate and butyl-methacrylate. Eight reactivity ratios were determined in all the 8 experiments. These determinations were done in accordance with the equation: $\mathrm{m}_{1} / \mathrm{m}_{2}=\mathrm{M}_{1}\left(\mathrm{r}_{1} \mathrm{M}_{1}+\mathrm{M}_{2}\right) / \mathrm{M}_{2}\left(\mathrm{M}_{1}+\mathrm{r}_{2} \mathrm{M}_{2}\right)$. Although free radical polymerization was used instead of RAFT polymerization, the effect of the latter on the reactivity ratios is known to be negligible ${ }^{6}$. One set of two experiments is needed to determine two reactivity ratios $\left(\mathrm{r}_{1}, \mathrm{r}_{2}\right)$. In the equation, $\mathrm{m}_{1} / \mathrm{m}_{2}=\mathrm{M}_{1}\left(\mathrm{r}_{1} \mathrm{M}_{1}+\mathrm{M}_{2}\right) / \mathrm{M}_{2}\left(\mathrm{M}_{1}+\mathrm{r}_{2} \mathrm{M}_{2}\right), \mathrm{m}_{1}$ and $\mathrm{m}_{2}$ are determined from the NMR spectra as noted in the experimental part. $\mathrm{M}_{1}$ and $\mathrm{M}_{2}$ are, as mentioned, the mole fractions of the monomer 1 and 2 in the reaction system. Therefore there are two equations with two unknowns $r_{1}$ and $r_{2}$. 
TABLE-1

OVERALL RESULTS OF REACTIVITY RATIOS. RESULTS OF DUPLO EXPERIMENTS ARE SHOWN IN BRACKETS

\begin{tabular}{|c|c|c|c|c|c|c|c|}
\hline Monomer 1 & Monomer 2 & $\mathrm{M}_{1}$ & $\mathrm{M}_{2}$ & $\mathrm{~m}_{1}$ & $\mathrm{~m}_{2}$ & $\mathrm{r}_{1}$ & $r_{2}$ \\
\hline MMA & BMA & & & & & 0.79 & 1.27 \\
\hline MMA & MAA & & & & & $1.18 / 2.61$ & $0.63 / 0.43$ \\
\hline BMA & MAA & & & & & 1.20 & 0.75 \\
\hline MMA & HEMA & & & & & 0.824 & 0.63 \\
\hline BMA & HEMA & & & & & - & - \\
\hline MMA & 3 & 0.33 & 0.67 & 0.25 & 0.75 & \multirow{2}{*}{1.17} & \multirow{2}{*}{1.84} \\
\hline MMA & 3 & 0.67 & 0.33 & 0.64 & 0.36 & & \\
\hline BMA & 3 & 0.33 & 0.67 & 0.22 & 0.78 & \multirow{2}{*}{0.64} & \multirow{2}{*}{1.80} \\
\hline BMA & 3 & 0.67 & 0.33 & 0.40 & 0.60 & & \\
\hline MMA & 5 & 0.33 & 0.67 & $0.18(0.22)$ & $0.82(0.78)$ & \multirow{2}{*}{$1.13(0.47)$} & \multirow{2}{*}{$2.99(1.66)$} \\
\hline MMA & 5 & 0.67 & 0.33 & $0.58(0.52)$ & $0.42(0.48)$ & & \\
\hline BMA & 5 & 0.33 & 0.67 & $0.37(0.35)$ & $0.63(0.65)$ & \multirow{2}{*}{$0.54(0.53)$} & \multirow{2}{*}{$0.57(0.66)$} \\
\hline BMA & 5 & 0.67 & 0.33 & $0.62(0.65)$ & $0.38(0.39)$ & & \\
\hline
\end{tabular}

The initial feed ratios of the monomers in the reaction mixture are estimated from the equations: $\mathrm{M}_{21} \cong \mathrm{r}_{1} /\left(2+\mathrm{r}_{1}\right)$ and $M_{22} \cong 2 /\left(2+r_{2}\right)^{6} \cdot M_{21}$ is the initial feed ratio of the monomer 2 in the first experiment, whereas $\mathbf{M}_{22}$ is the initial feed ratio of the monomer 2 in the second experiment. $r_{1}$ and $r_{2}$ are the reactivity ratios. Assuming $r_{1}=r_{2}=1$ (for a completely random polymerization), we get: $\mathrm{M}_{21}=1 / 3$ and $M_{22}=2 / 3$. In this context, two reaction mixtures were prepared, one containing ca. $33 \mathrm{~mol} \%$ of monomer 1 and $c a .67 \mathrm{~mol} \%$ of monomer 2 (as seen in the experimental part, polymer synthesis).

The overall results of the obtained reactivity ratios are given in Table-1. The reactivity ratios for the copolymerizations of butyl-methacrylate-methyl methacrylate, methyl methacrylatebutyl-methacrylate and methyl methacrylate-HEMA (2hydroxyethyl methacrylate, $\mathrm{C}_{6} \mathrm{H}_{10} \mathrm{O}_{3}$ ) are included as well ${ }^{7}$. Despite the moderate accuracy of some numbers all the values displayed in Table-1 for $r_{1}$ and $r_{2}$ are suitably close to 1 and therefore, suggest random copolymerization in all cases. In the experiments of the copolymerizations of monomer $\mathbf{3}$ and 5 with either methyl methacrylate and butyl-methacrylate $r_{2}$ $>\mathrm{r}_{1}$, meaning that $\mathrm{k}_{22} / \mathrm{k}_{21}>\mathrm{k}_{11} / \mathrm{k}_{12}$. This result indicates that $\mathbf{3}$ and $\mathbf{5}$ are preferred in the propagation if the chains end with these same monomers. This preference may be explained by specific interaction between the radical chain end and the new reacting monomer. In the case of $\mathbf{3}$ this interaction stems from $\pi-\pi$ stacking, while hydrogen bonding is involved in the case of 5.

\section{Conclusion}

We extended the work of Voss et al. ${ }^{1}$ and Wouters et al. ${ }^{2}$ and presented a full characterization of monomers $\mathbf{3}$ and $\mathbf{5}$.
Free radical polymerization was employed to copolymerize monomers 3 and 5 with methyl methacrylate and butylmethacrylate. NMR spectroscopy was utilized to study the composition of these copolymers at low conversion. In addition reactivity ratios were calculated. The reported values are in the range 0.6-3 and indicate rather random composition. This conclusion proves that the supposition made by former researchers ${ }^{1,2}$ regarding random composition of the polymers obtained by RAFT- copolymerization is justified.

\section{REFERENCES}

1. R.W.J. Voss, G.A. Roescher and H.A.M. Biemans, Crosslinkable Polymeric Materials with Controlled Melt-Flow Behaviour. Report of TNO Industrial Technology Eindhoven, Polymer Products and Coatings, Eindhoven, The Netherlands (2000).

2. M.E.L. Wouters, H.A.M. Biemans, R. Voss and M.J. Monteiro, Effect of Pendant Functionality and Molecular Weight on Some Thermal Properties of RAFT-Polymers. Unpublished manuscript. TNO Industrial Technology Eindhoven, The Netherlands. Dutch Polymer Institute (DPI), 5600 AX, Eindhoven, The Netherlands (2004).

3. G. Challa, Polymer Chemistry; An Introduction, Ellis Horwood Limited (1993).

4. K.B. Wiles, Determination of Reactivity Ratios for Acrylonitrile/Methyl Acryalte Radical Copolymerization via Non-linear Methodologies Using Real Time FTIR, Master's Thesis in Chemistry, Faculty of Virginia Polytechnic and State University, August 2002, Blacksburg, Virginia; http://scholar.lib.vt.edu/theses/available/etd-09022002-112751/.

5. P.W. Tidwell and G.A. Mortimer, J. Polym. Sci. Part A, 3, 369 (1965).

6. K. Matyjaszewski and T.P. Davis, Handbook of Radical Polymerization, John Wiley \& Sons, Inc. Canada (2002).

7. J. Brandrup and E.H. Immergut, Editors with the Collaboration of W. McDowell; Polymer Handbook, Jonh Wiley \& Sons, Inc. New York, edn 2 (1975). 